\title{
Oviposition Response of the Mosquito, Culex quinquefasciatus to the Secondary Metabolite(s) of the Fungus, Trichoderma viride
}

\author{
I Geetha, KP Paily, V Padmanaban, K Balaraman+
}

Vector Control Research Centre (Indian Council of Medical Research), Indira Nagar, Pondicherry 605 006, India

Secondary metabolites produced by Trichoderma viride, a deuteromycetes fungus, under submerged culture condition were formulated and evaluated for oviposition attractancy against gravid females of Culex quinquefasciatus mosquito. At a concentration of $10 \mu \mathrm{g} \mathrm{ml}^{-1}$ the formulation showed remarkable attractancy with an oviposition active index (OAI) of +0.52 . When the oviposition attractancy of the formulation was compared with a known oviposition attractant, p-cresol, both at $10 \mu \mathrm{g} \mathrm{ml}^{-1}$, the former was found to be more attractive to result in $70 \%$ egg laying than the later with $30 \%$ egg laying. Thin layer chromatography fractions of the secondary metabolites showed that a fraction with $R f$ value of 0.88 was highly active as oviposition attractant with an OAI of +0.65 . Further work on identification of the active principle(s) of the microbial formulation might lead to an oviposition attractant useful in mosquito vector management.

Key words: Trichoderma viride - secondary metabolites - mosquito oviposition attractancy - Culex quinquefasciatus

Mosquitoes are known to locate their specific hosts and oviposition sites by sensing chemical signals, besides various physical stimuli, that are detected by sensory receptors on the antennae (Davis \& Bowen 1994). By using oviposition attractants, vector mosquitoes could be attracted to chosen sites for laying eggs. Various chemicals serve as oviposition attractants for mosquitoes even when present in relatively small quantities (Beehler \& Mulla 1993). Oviposition attractants are known to be produced by microorganisms also (Hazard et al. 1967, Rockett 1987, Hasselschwert \& Rockett 1988, Beehler et al. 1994). Among deuteromycetes fungi, Trichoderma species are known to produce aromatic/volatile secondary metabolite(s) (Kikuchi et al. 1974, Keszler et al. 2000, SarhyBagnon et al. 2000, Kalyani et al. 2000). In the present study secondary metabolite(s) produced by the fungus Trichoderma viride was evaluated for oviposition attractancy against gravid females of Culex quinquefasciatus and the results are presented in this paper.

\section{MATERIALS AND METHODS}

A natural strain of T. viride (F24), obtained from the culture collection of Vector Control Research Centre (VCRC) was subcultured on Sabouraud Dextrose Agar (SDA) (glucose $40 \mathrm{~g}$; peptone $10 \mathrm{~g}$; agar $20 \mathrm{~g}$; distilled water $1000 \mathrm{ml} ; \mathrm{pH} 4.5-5.0$ ) slants and incubated for 5 days to attain sporulation. Then a loopful of spores were inoculated to $50 \mathrm{ml}$ Sabouraud Dextrose Broth (SDB) (glucose $40 \mathrm{~g}$; peptone $10 \mathrm{~g}$; agar $20 \mathrm{~g}$; distilled water $1000 \mathrm{ml}$; $\mathrm{pH} 4.5-5.0$ ) in a $250 \mathrm{ml}$ conical flask and incubated on a rotary shaker (New Brunswuck Scientific Co., New Jersey,

${ }^{+}$Corresponding author. Fax: +91-413-272041. E-mail: vcrc@vsnl.com

Received 24 June 2002

Accepted 25 October 2002
USA) at $110 \mathrm{rpm}$ and at $30^{\circ} \mathrm{C}$ for 3 days. From the seed culture, $2 \%$ of the inoculum was transferred to $200 \mathrm{ml}$ of SDB and incubated for 15 days at the above mentioned conditions. The culture was filtered through Whatman no.1 filter paper, the mycelial mass was discarded, and the culture filtrate was lyophilized. The residue was dissolved in 50\% ethanol at a ratio of $500 \mathrm{mg}$ of residue in $10 \mathrm{ml}$ of ethanol. This formulation was code named as VCRC F24 and used for oviposition attractancy tests.

Determination of optimum concentration of VCRC F24 and p-cresol for oviposition attractancy test - Threeday-old $C x$. quinquefasciatus Say female mosquitoes, an indigenous strain obtained from a laboratory colony maintained at VCRC, were fed on fowl blood and maintained for two days on raisins at $28 \pm 2^{\circ} \mathrm{C}$ and $70-80 \% \mathrm{RH}$. Gravid female mosquitoes were used for the determination of oviposition attractancy using standard procedure (WHO 1963). Different concentrations ( $5 \mu \mathrm{g} \mathrm{ml}^{-1}, 10 \mu \mathrm{g} \mathrm{m}{ }^{-1}$ and $15 \mu \mathrm{g} \mathrm{ml}^{-1}$ ) of VCRC F24 and a known oviposition attractant, $p$-cresol (a volatile pentane), was prepared in tap water. In the case of $p$-cresol, a stock solution of $1 \mathrm{mg}$ $\mathrm{ml}^{-1}$ was made in ethanol and diluted to the required levels with tap water. Tap water with equal amount of ethanol served as control for VCRC F24 and $p$-cresol. Two hundred $\mathrm{ml}$ of each of the test/control solutions held in disposable bowls (capacity, $250 \mathrm{ml}$ ) were placed in the floor of a mosquito cage (size, 55 x 55 x $55 \mathrm{~cm}$ ). One hundred numbers of fully gravid female mosquitoes were released into the cage. For each test at any given time, not more than two bowls were kept in the opposite corners of the cage. The cages were kept at $28 \pm 2^{\circ} \mathrm{C}$ and $70-80 \%$ RH. On each occasion, the experiment was set up at 16:00 $\mathrm{h}$ and observations for presence of egg rafts, if any, were made at 10:00 $\mathrm{h}$ the next day. The number of egg rafts laid in each bowl were counted and the percentage of egg rafts laid in each concentration was calculated from the total number of egg rafts laid in both test and control solutions. Each experiment was repeated four times and on each occasion the position of the disposable cups were changed. 
Oviposition active index (OAI) of test material - OAI of any test material was determined by placing in a cage, one bowl containing test material and another bowl containing tap water with ethanol as control. OAI of different concentrations of the VCRC F24 and $p$-cresol was calculated by using the formula (Kramer \& Mulla 1979)

$$
\mathrm{OAI}=\frac{\mathrm{Nt}-\mathrm{Ns}}{\mathrm{Nt}+\mathrm{Ns}}
$$

where, Nt is the number of egg rafts laid in test solution and Ns is the number of egg rafts laid in control.

As suggested by Kramer and Mulla (1979), compounds with an OAI of +0.3 and above are considered as attractants, while those with -0.3 and below are considered as repellents.

Oviposition attractancy of VCRC F24 in comparison with p-cresol - The oviposition attractancy of VCRC F24 was compared with $p$-cresol by testing them at their optimal concentrations required for oviposition attractancy i.e., $10 \mu \mathrm{g} \mathrm{ml}^{-1}$. This experiment was conducted by keeping two disposable bowls in a cage, one with VCRC F24 and the other with $p$-cresol as oviposition media, at the opposite corners. The number of egg rafts laid in the oviposition bowls were counted and percentage of egg rafts laid in each bowl was calculated from the total number of egg rafts laid in both VCRC F24 and $p$-cresol.

Attempts were made to isolate the active principle of the secondary metabolite and for this, the lyophilized culture filtrate was extracted with methanol, the solvent was evaporated and the residue was re-dissolved in methanol (200 $\mathrm{mg}$ in $25 \mathrm{ml}$ ). The dissolved residue was subjected to thin layer chromatography (TLC) analysis. Both analytical (0.25 mm layer thickness) and preparative $(0.5 \mathrm{~mm}$ layer thickness) TLC were carried out on silica gel plates using chloroform-methanol (70:30) as solvent system and spots were visualized by exposing the plates to iodine vapours. From the preparative TLC plates, major bands (at Rf 0.92, $0.88,0.84,0.24$ and 0.12 ) were scrapped out and extracted with methanol. The purity of the bands was tested on analytical TLC and the solvent was evaporated. The residue was dissolved in ethanol and tested against gravid $C x$. quinquefasciatus at a concentration of $10 \mu \mathrm{g} \mathrm{ml}^{-1}$. Each fraction was tested for OAI individually along with tap water containing ethanol as control.

\section{RESULTS}

Optimum concentration for oviposition attractancy In the case of VCRC F24, among the three concentrations tested, $10 \mu \mathrm{g} \mathrm{ml}^{-1}$ and $15 \mu \mathrm{g} \mathrm{ml}^{-1}$ attracted more number of gravid females for oviposition and that resulted in 75.9 and $75.9 \%$ egg rafts, respectively (Table). With respect to $p$-cresol, maximum oviposition was observed at $10 \mu \mathrm{g}$ $\mathrm{ml}^{-1}$ with $73.6 \%$ egg rafts. Hence the optimum concentration for oviposition attractancy of both VCRC F24 and $p$ cresol was determined to be $10 \mu \mathrm{g} \mathrm{ml}^{-1}$.

$O A I$ - The data on the OAI of VCRC F24 and $p$-cresol are presented in the Table. At $5 \mu \mathrm{g} \mathrm{ml}^{-1}$ level VCRC F24 was attractive with an $\mathrm{OAI}$ of +0.4 . At concentrations of $10 \mu \mathrm{g} \mathrm{ml}^{-1}$ and $15 \mu \mathrm{g} \mathrm{ml}^{-1}$ the OAI was +0.52 . In the case of $p$-cresol, at $5 \mu \mathrm{g} \mathrm{ml}^{-1}$ level it was not attractive to gravid females as the OAI was +0.2 . With increasing concentration of $10 \mu \mathrm{g} \mathrm{ml}^{-1}$ and $15 \mu \mathrm{g} \mathrm{ml}^{-1}$, the OAI was respectively +0.47 and +0.32 .

Oviposition attractancy of VCRC F24 in comparison with p-cresol - The data on the percentage of egg rafts laid by gravid $C x$. quinquefasciatus in VCRC F24 compared to that in $p$-cresol is illustrated in Fig. 1. The results indicated that VCRC F24 was more attractive with $68.8 \%$ of egg rafts than $p$-cresol with $29.5 \%$ egg rafts.

Oviposition attractancy of TLC fractions - Among the TLC fractions (Fig. 2) tested at $10 \mu \mathrm{g} \mathrm{ml}^{-1}$ level, those with Rf values $0.92,0.88,0.84$ and 0.24 attracted gravid $C x$. quinquefasciatus for oviposition. OAI of these fractions were respectively, $+0.57,+0.65,+0.48$ and +0.3 .

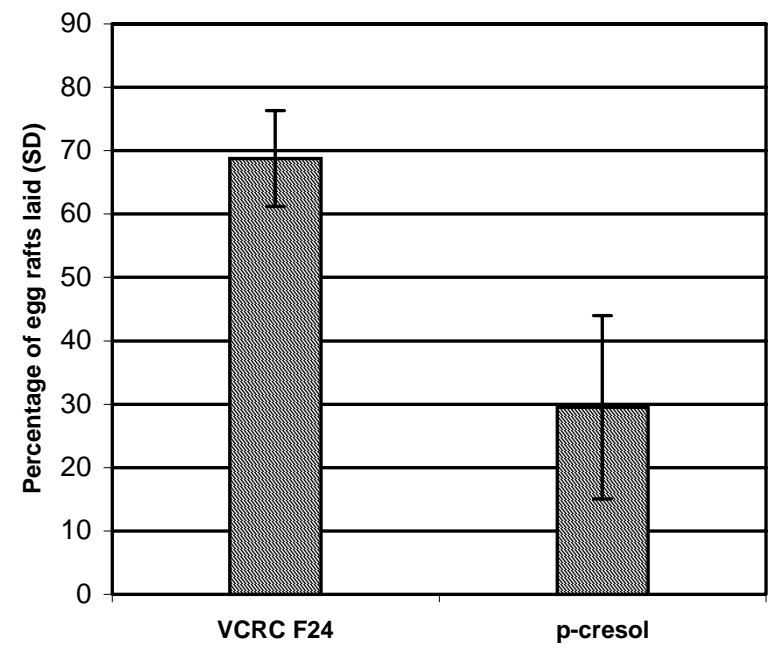

Fig. 1: oviposition response of gravid Culex quinquefasciatus to Vector Control Research Centre F24 (VCRC F24) and $p$-cresol at $10 \mu \mathrm{g} \mathrm{ml}^{-1}$ when they were exposed to both the test materials in the same cage.

TABLE

Oviposition response of gravid Culex quinquefasciatus when they were exposed to varying concentrations of VCRC F24 and $p$-cresol in different cages

\begin{tabular}{lcccc}
\hline $\begin{array}{l}\text { Concentration } \\
\text { in } \mu \mathrm{g} \mathrm{ml}^{-1}\end{array}$ & $\begin{array}{c}\text { Percentage oviposition } \\
\text { in VCRC F24 } \pm \text { SE }\end{array}$ & $\begin{array}{c}\text { OAI of } \\
\text { VCRC F24 }\end{array}$ & $\begin{array}{c}\text { Percentage oviposition } \\
\text { in } p \text { - cresol } \pm \text { SE }\end{array}$ & $\begin{array}{c}\text { OAI of } \\
p \text {-cresol }\end{array}$ \\
\hline 5 & $69.89 \pm 7.11$ & 0.40 & $59.95 \pm 7.18$ & 0.20 \\
10 & $75.93 \pm 2.56$ & 0.52 & $73.60 \pm 3.59$ & 0.47 \\
15 & $75.86 \pm 1.55$ & 0.52 & $65.99 \pm 4.17$ & 0.32 \\
\hline
\end{tabular}

OAI: oviposition active index; VCRC: Vector Control Research Centre 


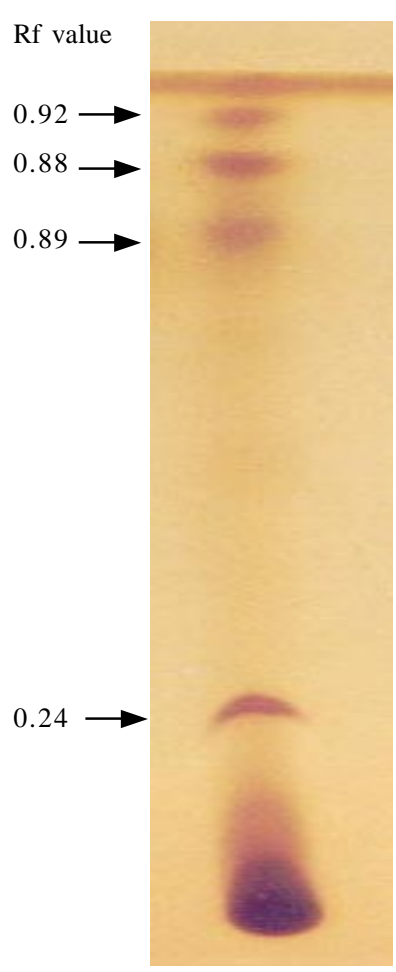

Fig. 2: thin layer chromatography pattern of Vector Control Research Centre F24

\section{DISCUSSION}

Various volatile chemicals produced by microorganisms are known to be attractive to gravid mosquitoes to locate oviposition sites for egg laying (Rockett 1987). The bacterium, Aerobacter aerogenes, isolated from hay infusion has been reported to produce chemicals which stimulated gravid females of Aedes aegypti (L.) and $C x$. quinquefasciatus Say to lay eggs (Hazard et al. 1967). Similarly, protein hydrolysate solutions with their bacterial contaminants have been found to be attractive to gravid Cx. quinquefasciatus (Beehler et al. 1994). T. viride, a deuteromycetes fungus, is widely used in agriculture as a biocontrol agent against fungal diseases of plants. Under submerged culture conditions it produces many mycotoxins like trichodermin, alamethicin, trichoviridin, trichotoxin etc. and a volatile, aromatic secondary metabolite, 6-pentyl-alpha- pyrone (Eveleigh 1985).

In the present study, the metabolite(s) was found to exhibit a novel activity viz. mosquito oviposition attractancy. It was observed that, when tested at concentrations of $5 \mu \mathrm{g} \mathrm{ml}^{-1}, 10 \mu \mathrm{g} \mathrm{ml}^{-1}$ and $15 \mu \mathrm{g} \mathrm{ml}^{-1}$, more number of gravid females were attracted to test solutions containing VCRC F24 than to the control solution. Increase in the concentration of the test solution from $5 \mu \mathrm{g} \mathrm{ml}^{-1}$ to $10 \mu \mathrm{g}$ $\mathrm{ml}^{-1}$ was found to increase the percentage of egg rafts laid. However, further increase in concentration to $15 \mu \mathrm{g}$ $\mathrm{ml}^{-1}$ did not increase the percentage oviposition and hence, the lowest concentration at which the highest percentage of egg rafts laid, i.e. $10 \mu \mathrm{g} \mathrm{ml}^{-1}$, was considered as the optimum concentration required for oviposition attracta- ncy. This was true with that of different concentrations of $p$-cresol also and $10 \mu \mathrm{g} \mathrm{ml}^{-1}$ was considered as optimum for comparing the effectiveness of VCRC F 24.

With respect to the OAI, a concentration of $5 \mu \mathrm{g} \mathrm{ml}^{-1}$ of VCRC F24 was attractive to gravid female mosquitoes $(\mathrm{OAI}+0.3)$ where as $p$-cresol did not show oviposition attractancy at this concentration $(\mathrm{OAI}+0.2) . P$-cresol has been reported to be an attractant to Ae. triseriatus at a concentration of $3 \mu \mathrm{g} \mathrm{ml}^{-1}$ (Bentley et al. 1979). The higher dosage of $p$-cresol required during the present study might be due to the difference in the species of the mosquitoes against which it was tested. Interestingly, VCRC F24 showed higher oviposition attractancy than $p$-cresol.

Thin layer chromatography results showed that among the four bands which were positive for oviposition attractancy, the one with Rf value of 0.88 had higher attractancy with an OAI of +0.65 . Compared to the crude material (VCRC F24 formulation) the attractancy was found to be more with the fraction. The production of the oviposition attractant factor can be enhanced by optimising the media components and cultivation conditions.

Oviposition attractants are important as they could be used in mosquito trapping for identification, surveillance and control. The present study shows that the microbial formulation, VCRC F24 from T. viride is attractive to gravid females of $C x$. quinquefasciatus and further work on the identification of the active principle(s) and enhancement of the production or synthesis of analogues might result in a product, which could be used in integrated vector management.

\section{ACKNOWLEDGEMENTS}

To Dr PK Das, Director, Vector Control Research Centre for suggestions and encouragement, to Dr SL Hoti and Dr Nisha Mathew for their help in chromatography and to $\mathrm{Mr} \mathrm{A}$ Ramamoorthy and Mr S Venugopalan for their technical assistance.

\section{REFERENCES}

Beehler WJ, Mulla SM 1993. Effect of the insect growth regulator methoprene on the ovipositional behavior of Aedes aegypti and Culex quinquefasciatus. J Am Mosquito Control Assoc 9: 13-16.

Beehler WJ, Millar GJ, Mulla SM 1994. Protein hydrolysates and associated contaminants as oviposition attractants for the mosquito Culex quinquefasciatus. Med Vet Entomol 8: 381-385.

Bentley MD, Mc Daniel NL, Yatagai M, Lee HP, Maynard $\mathrm{R}$ 1979. p-cresol: an oviposition attractant of Aedes triseriatus. Environ Entomol 8: 206-209.

Davis EE, Bowen FM 1994. Sensory physiological basis for attraction in mosquitoes. J Am Mosquito Control Assoc 10: 316-325.

Eveleigh DE 1985. Trichoderma. In AL Demain, NA Solomon (eds), Biology of Industrial Microorganisms, The Benjamin/ Cummings Publ Company Inc, California, p. 487-509.

Hasselschwert D, Rochett CL 1988. Bacteria as ovipositional attractants for Aedes aegypti (Diptera: culicidae). Great Lakes Entomol 21: 163-168.

Hazard EI, Mayer MS, Savage KE 1967. Attraction and oviposition stimulation of gravid female mosquitoes by bacteria isolated from hay infusions. J Am Mosquito Control Assoc 27: 133-136.

Kalyani A, Prapulla SG Karanth NG 2000. Study on the 
production of 6-pentyl-alpha-pyrone using two methods of fermentation. Appl Microbiol Biotechnol 53: 610-612.

Keszler A, Forgacs E, Kotai, L, Vizcaino JA, Monte E, Garcia-Acha I 2000. Separation and identification of volatile components in the fermentation broth of Trichoderma atroviride by solid-phase extraction and gas chromatography-mass spectrometry. J Chromatogr Sci 38: 421-424. Kikuchi T, Mimura T, Harimaya K, Yano H, Arimoto T 1974. Volatile metabolite of aquatic fungi. Identification of 6-pentyl-alpha-pyrone from Trichoderma and Aspergillus species. Chem Pharm Bull 22: 1946-1948.

Kramer LW, Mulla SM 1979. Oviposition attractants and repellents of mosquitoes: oviposition responses of Culex mosquito to organic infusions. Environ Entomol 8: 11111117.

Rockett CL 1987. Bacteria as an oviposition attractant for Culex pipiens (Diptera: Culicidae). Great Lakes Entomologist 20: 150-151.

Sarhy-Bagnon V, Lozano P, Saucedo-Castaneda G, Roussos S 2000. Production of 6-pentyl-alpha-pyrone by Trichoderma harzianum in liquid and solid state cultures. Process Biochem 36: 103-109.

WHO - World Health Organization 1963. Technical Report Series, No. 265. 